\title{
HOW LONG WILL THE COVID-19 PANDEMIC LAST?
}

\author{
Peter SZABÓ, Miroslava FERENCOVÁ* \\ Technical University of Košice, Faculty of Aeronautics, Rampová 7, 04121 Košice, Slovakia \\ *Corresponding author. E-mail: miroslava.ferencova@student.tuke.sk; tel.: +421 903356789
}

\begin{abstract}
Globalization, a process by which the world is becoming interconnected by trade and cultural exchange, is very characteristic of the current world. Modern technologies allow us to receive, investigate and research global data and information. A degree of globalization can be defined for an individual country, a group of nations or a whole world. The authors are researching the duration of the vaccination against the COVID-19 (hereafter ,vaccination“). The research applies to the individual countries (Slovakia and UK), the countries group (the EU), and the whole world. It is based on the vaccination data from January and February 2021. The results provide an estimation of the duration of the pandemics. It can be updated at any time following the newly updated data.
\end{abstract}

Keywords: public health; collective immunity; linear regression; programming in Python; data analysis

\section{INTRODUCTION}

This paper is dealing with the vaccination against the COVID-19 virus. It is known that the pandemic vanishes when a population obtains collective immunity. For obtaining collective immunity, $60-70 \%$ of the population has to be immune against the virus. The immunity can be obtained after overcoming disease or after vaccination.

In the paper, the authors are researching how long the vaccination against COVID-19 will last. To answer this question, the authors used the research method of regression analysis. The use of this method is described in detail in the following chapter. The calculations were performed for different communities: the individual countries - Slovakia and UK, the countries group - the European Union and the whole world. All calculations described in this paper provide the estimations for vaccination duration against COVID-19 and can be updated anytime based on the actual data.

\section{RESEARCH METHODS}

The research on the duration of the vaccination is done by using the regression analysis; it is based on February vaccination data. For the regression analysis, the following inputs are required: population size ( (data), required percentage of the vaccination ( $v a c)$, and the number of doses for the vaccination (dose). The data $\left[x_{i}, y_{i}\right]$ can be displayed in the coordinate system; the values of $x_{i}$ indicate the number of days while the variable $y_{i}$ indicate the number of people vaccinated in $x_{i}$ days. Under the regression analysis, it is possible to find the regression line.

$$
y=k x+q
$$

that is located in the "closest“ position to the points of the coordinate system $\left[x_{i}, y_{i}\right]$. Based on the other inputs, it is possible to calculate the minimum number of the vaccines needed to reach the collective immunity of the population:

$$
y=\text { dose } * \text { pop } * \text { vac } / 100
$$


When substituting this number to equation (1), the result will show an estimated amount of the days needed for vaccinating as per the January data.

\section{HOW LONG WILL THE VACCINATION LAST?}

It is known that a pandemic/epidemic terminates when the population obtains collective immunity. The population receives collective immunity when $60-70 \%$ of the population is immune to the virus. The immunity can be obtained after vaccination or when a person has already overcome a disease. Using the linear regression and based on the available data, it is possible to estimate how long the whole population vaccination will last.

\subsection{A duration of vaccination in Slovakia}

In January and February 2021, Slovakia was providing the following data about vaccination:

$\mathrm{Pop}=5466000$

Data $=[(6,6618),(13,46243),(20,85957),(27,121245),(34,178442),(42,268844)]$

The first value in the brackets indicates the number of days since the vaccination started. The second value is the number of people already vaccinated to that day. For example, in Slovakia, on the $6^{\text {th }}$ of January 2021, there were 6618 people vaccinated. Hence, if we maintain this pace of vaccination, how much time will be needed to vaccinate $60 \%$ of the Slovak population? The model is not researching the vaccination organization, i.e., the number of vaccines, capacity, etc. It is based only on the facts known from the provided numbers. We can now assign the regression line (1) where the variable $x$ indicates the number of days, and $y$ is the number of vaccinated people to the available data. The model generates the following results:

For vaccinating $60 \%$ of the Slovak population, there are still 818 days (2.24 years) necessary. On the $23^{\text {rd }}$ of February 2021 , the $\%$ of vaccination was $3.6113 \%$.

$y=8103 x-68098$ - the equation of the regression line of vaccination in Slovakia in February 2021.

\subsection{A duration of vaccination in the European Union}

To get the results for the EU, the online available data were used (vaccination in 2021 and the population size).

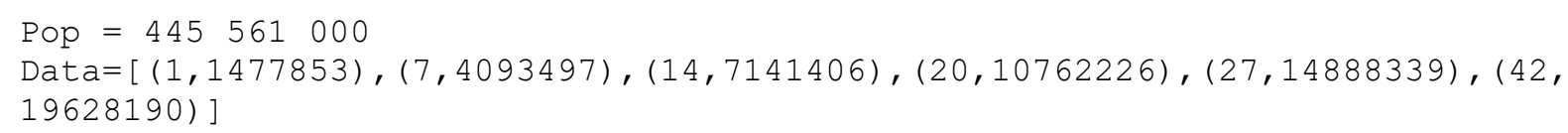

These inputs generate the following outputs:

For vaccinating $60 \%$ of the EU population, there are still 1098 days (3.01 years) necessary. On the $23^{\text {rd }}$ of February 2021, the \% of vaccination was $3.1716 \%$.

$y=486013 x+791561$ - the equation of the regression line of vaccination in the EU in February 2021.

\subsection{A duration of vaccination in the United Kingdom}

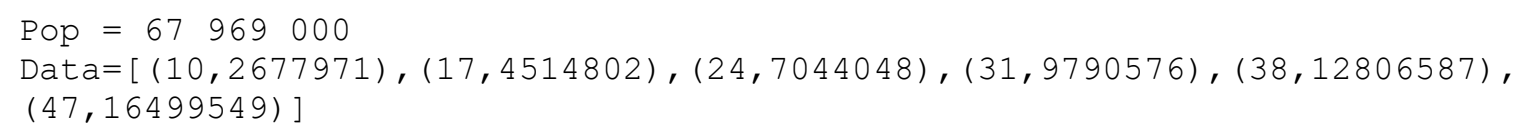


These inputs generate the following outputs:

For vaccinating $60 \%$ of the world population, there are still 218 days ( 0.597 year) necessary. On the $22^{\text {nd }}$ of February 2021 , the $\%$ of vaccination was $13.653 \%$.

$y=381602 x-1722845$ - the equation of the regression line of vaccination in the UK in February 2021.

\subsection{A duration of vaccination in the world}

$\mathrm{Pop}=7809575000$

Data $=[(6,16326929),(13,35780021),(20,54315120),(27,82980899),(34,115614565)$ $,(42,160070774)]$

These inputs generate the following outputs:

For vaccinating $60 \%$ of the world population, there are still 2184 days (5.98 years) necessary. On the $23^{\text {rd }}$ of February 2021 , the $\%$ of vaccination was $1.3840 \%$.

$y=4300763 x-22405525$ - the equation of the regression line of vaccination in the world in February 2021.

All data, numbers of vaccinations, and the population size were obtained from the Internet sources [3].

\section{THE IMPLEMENTATION OF CALCULATION}

The calculations were implemented by the SageMath system (Python) [5]. The executable source code is under the link in [4]. After updating the data, there is a possibility to use the calculations for different countries and the periods, too.

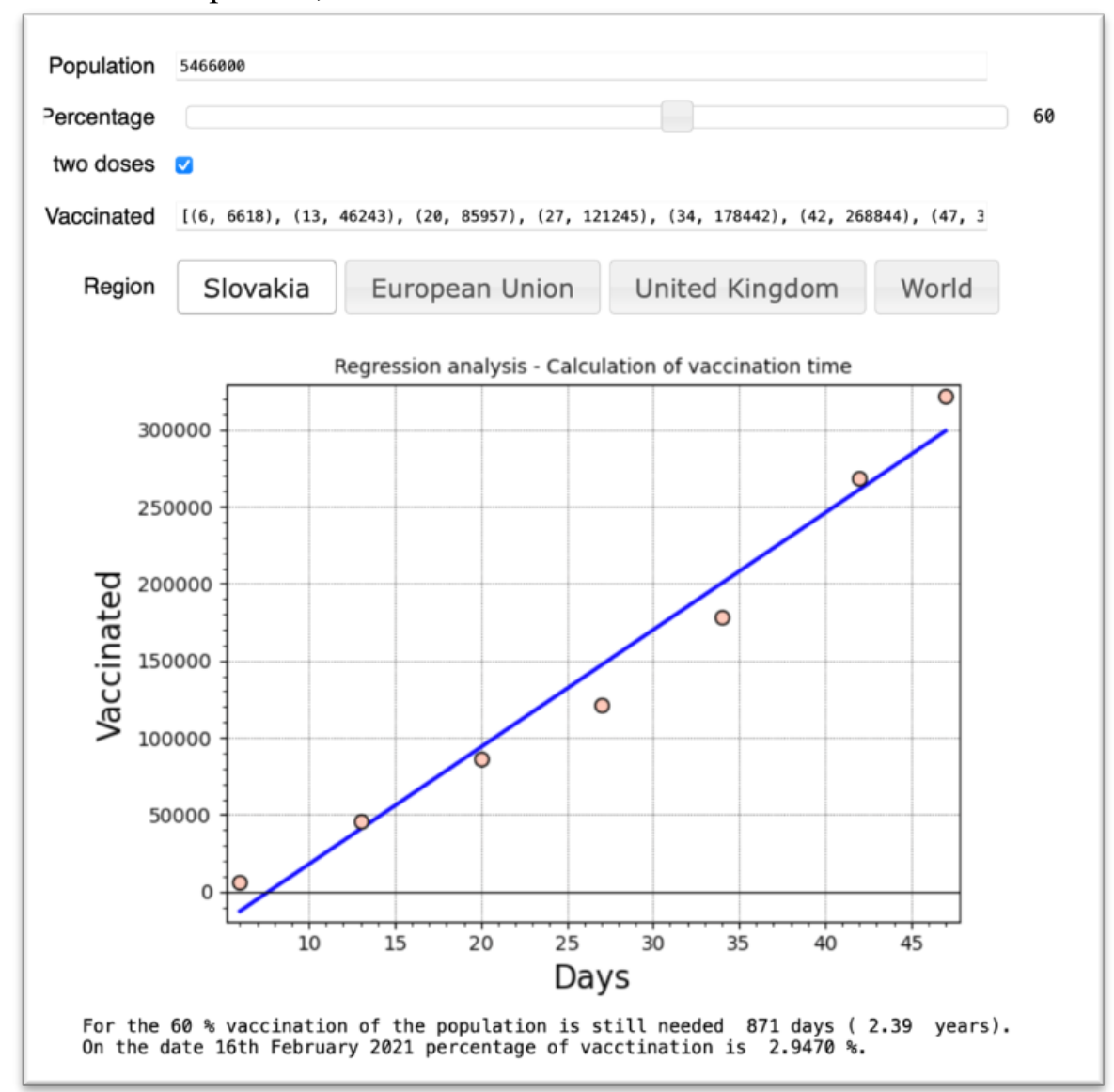

Figure 1 World COVID - 19 Vaccination, February 2021 


\section{CONCLUSION}

The calculations in this paper indicate how long the vaccination might last in different communities. The vaccination itself might take a shorter time; it is expected to accelerate with the vaccines production. We can update the calculations at any time; in other words, if we have the updated data. With updated data, the estimations will be more precise, which means gaining a collective immunity for the individual population and consequently, the end of the pandemic. We realized all these considerations and calculations based on global data. The research was recognized within the study of linear regression.

\section{References}

[1] Szabó, P.; Ferencová, M.; Szabóová, E. Assessment of pandemics impact on public health and aviation sector by using mathematical modeling. In: Acta Avionica. Košice (Slovakia): Faculty of Aeronautics. Vol. 22, No. 2 (2020), P. 1-8. ISSN 1335-9479. DOI: https://doi.org/10.35116/aa.2020.0011

[2] Szabó, P.; Galanda, J. Sage math for education and research. 15th International Conference on Emerging eLearning Technologies and Applications (ICETA), 2017, P. 469-472. ISBN 978-1-53863294-9. IEEE. DOI: 10.1109/ICETA.2017.8102535

[3] Vaccination data (2021): https://github.com/owid/covid-19-data/blob/master/public/data/ vaccinations/vaccinations.csv

[4] An estimate of vaccination duration (2021): http://people.tuke.sk/peter.szabo/vaccination.html

[5] SageMath - calculation (2021): https://www.sagemath.org/

[6] Linear Regression (2021): https://www.oxfordreference.com/view/10.1093/oi/authority.2011 0803100107226

Received 06, 2021, accepted 07, 2021

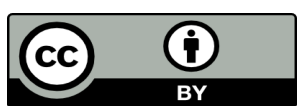

Article is licensed under a Creative Commons Attribution 4.0 International License 